\title{
Steel-Reinforced Polyethylene Pipe: Extrusion Welding, Investigation, and Mechanical Testing
}

\author{
The effects of welding methods, with and without preheat \\ conditions, on weld quality were investigated by visual and \\ radiographic inspections, and crystalline analysis
}

\author{
BY C. TIPPAYASAM AND A. KAEWVILAI
}

\begin{abstract}
This work presents extrusion welding with a square butt joint of V-shaped steel-reinforced polyethylene (SRPE) corrugated pipe. The SRPE pipe was welded in a single pass on the inside of the pipe. The welding temperature was controlled at $190^{\circ}-200^{\circ} \mathrm{C}$. The welding extruder was modified for controlling the travel speed and preheating conditions for welding. A high-density polyethylene (HDPE) rod was used as the welding filler metal, which was inserted into the extruder with a speed of $2.20 \mathrm{~m} / \mathrm{min}$. Welding progressed downhill from the overhead position with a travel speed of $3.0 \mathrm{~cm} / \mathrm{min}$. The effects of welding methods, with and without preheat conditions, on the weld quality were investigated by visual and radiographic inspections. From the results, the preheated welding condition showed complete fusion of the weld without any defects, while that of the nonpreheat exhibited a great number of voids inside the weld. The crystal structures of the preheated and nonpreheated welds were analyzed with an $\mathrm{x}$-ray diffractometer and compared with the HDPE base material. From mechanical testing, the weld from the preheat condition showed a good ability to endure the tension force of $46 \mathrm{MPa}$ and compressive stress of up to $0.41 \mathrm{MPa}$ at $5 \%$ deflection. In addition, it was found the welded SRPE could tolerate hydrostatic pressure of up to $0.18 \mathrm{MPa}$ without any water leakage when being used as a water-containing tank.
\end{abstract}

\section{KEYWORDS}

- Steel-Reinforced Polyethylene Pipe

- Extrusion Welding • Preheat

\section{Introduction}

High-density polyethylene (HDPE) pipe, well known as a type of thermoplastic pipe, is used instead of concrete and steel pipes for many applications, such as gas and fluid transfers, water/sewage drainages, and electrical and communication conduits (Refs. 1-3). The HDPE pipe shows many excellent properties, such as light weight, chemical resistance, and tolerance for decomposition (Ref. 4). Although HDPE pipe has

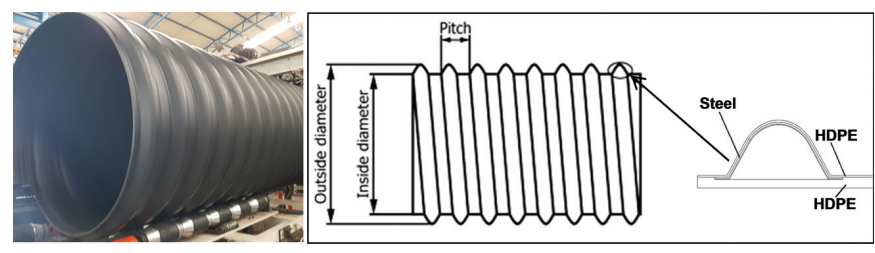

Fig. 1 - Steel-reinforced polyethylene corrugated pipe (doublewall V-shaped profile).

been appropriate for underground applications, it also has high ductility and low stiffness, which causes an unstable shape when it receives highly compressive forces (Refs. 3, 4). Recently, the strength of HDPE pipe has been improved by methods such as increasing the wall thickness, spiral shape designs, and reinforcements such as fiberglass and ceramic, etc. (Refs. 3-5).

Steel-reinforced polyethylene (SRPE) corrugated pipe is a kind of sandwich composite consisting of HDPE and galvanized steel (Refs. 6, 7). The internal and external walls are covered by HDPE, and the center layer is reinforced with galvanized steel with $V$ and $U$ spiral shapes (Refs. 8, 9), as shown in Fig. 1 . The SRPE has many advantages from the combined properties of HDPE and reinforced steel, such as high stiffness, high corrosion resistance, and better flexibility with steady structure (Refs. 8-10). As a result, there has been interest in using SRPE for underground applications such as drainage/sewage pipes and water storage tanks (Refs. 8-10). For fabrication and connection uses, SRPE is simple to weld at the HDPE joint by heating-fusion processes such as electrofusion belt, elastomeric seal, and heated tool welding (Refs. 11-14). However, these techniques are suitable for butt-joint welding on the outside of the pipe. It is difficult for completely welding on the inside of the pipe and other joints such as lap, corner, and T-shaped joints.

Extrusion welding is a thermal technique developed from hot gas/air welding for melting and joining thermoplastics and their composites (Refs. 14-18). The filler rod-based thermoplastic material is heated and extruded into a molten form at the joint area, which is welded after cooling. It also allows a large welding area with a single pass and good penetration (Refs. 19-20). Hot melt extrusion welding can be performed 


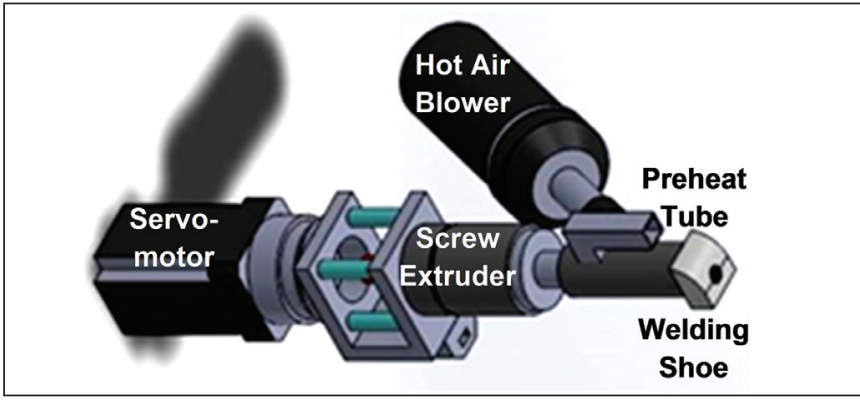

Fig. 2 - Welding extruder (Ref. 21).

by a manual welder or with semiautomation, and can weld on both the inside and outside of the pipe with various joint designs. The weld quality from extrusion could be controlled by welding parameters such as welding temperature, flow rate, and extrusion speed (Refs. 19, 20).

Based on our knowledge, the effects of preheating condition on weld quality, crystallinity, and strength of SRPE in extrusion welding have not been reported. Therefore, this work presents welding of V-shaped SRPE pipe (1200 mm diameter) by manual extrusion with preheat. The modified extruder with the preheat function was used for controlling heating conditions before welding. The effects of welding methods, with and without preheat conditions, on weld quality and the crystalline structure were also studied. In addition, the mechanical properties of the weld were further tested for considering the possibility of using welded pipe in unground applications such as water storage and sewage/drainage pipes.

\section{Experimental Procedures}

\section{Materials and Instruments}

Steel-reinforced polyethylene corrugated pipe (V-shaped double-wall pipe) with a diameter of $1200 \mathrm{~mm}$ (Refs. 8, 9) and 3.5-mm-diameter HDPE rod were supported by SR.PE GROUP Co. Ltd. The welding extruder produced from Metabo was modified with a servomotor and preheat function (Refs. 20, 21) as shown in Fig. 2. An infrared thermosensor (PROSKIT, MT-4612) was used for detecting the actual temperature of welding. The $\mathrm{x}$-ray radiographic tester was a product from General Electric Co. The crystal structures of the welds were analyzed by an x-ray diffractometer (XRD; a Philips X-Pert-MPD x-ray diffractometer). The tensile strength and stiffness of the welded specimens were tested, respectively, by a universal testing machine (UTM; Chengde Precision) and compressive tester (JINGMI).

\section{Welding and Investigation}

The SRPE pipes were prepared in a squared butt-joint configuration with a root opening of $5.0 \mathrm{~mm}$ and welded by extrusion at the tacking positions of $0,90,180$, and 270 deg, respectively. Before welding, the joint was prepared in the following two conditions: 1 ) welding with preheating at $150^{\circ} \mathrm{C}$ and 2) welding without preheating. The HDPE rod was inserted into the hot air extruder with the rate of $2.20 \mathrm{~mm} / \mathrm{min}$ and the controlled temperature of $190^{\circ}-200^{\circ} \mathrm{C}$ during the welding period. The travel speed and extruder speed were controlled at
$3.0 \mathrm{~cm} / \mathrm{min}$ and $200 \mathrm{rpm}$, respectively. After that, the SRPE was welded in a single pass on the inside of the pipe from an overhead position with downhill progression.

After welding, the shape, dimension, and quality of the welds were inspected by visual testing (VT) according to American Welding Society (AWS) Standard G1.10M:2001, Guide for the Evaluation of Hot Gas, Hot Gas Extrusion, and Heated Tool Butt Thermoplastic Welds (Ref. 22). The inside welds were investigated by radiographic testing (RT) using a phosphor imaging plate (D7 class) and the exposure parameters of $20 \mathrm{kV}, 2$ $\mathrm{mA}, 40 \mathrm{~s}$, and the FFD of $700 \mathrm{~mm}$. The radiographic images were developed by a computed scanner. After that, the welded specimens were characterized by XRD using $\mathrm{Cu}-\mathrm{K} \alpha$ as the radiation source $(\lambda=1.54 \AA)$ and $2 \theta$ ranging from 10 to $40 \mathrm{deg}$ with a scanning rate of $0.21 / \mathrm{s}$. The crystallinity was determined from the integrated area of amorphous and crystalline as follows: \%crystallinity $\left(X_{C}\right)=A_{C} /\left(A_{C}+A_{A}\right)$, where $A_{C}$ and $A_{A}$ are the crystalline and amorphous areas, respectively (Refs. 23-25). The crystalline thickness of the lamella was calculated by Scherrer equation as follows: $\tau=K \lambda / \beta \cos \theta$ where $\tau$ is the mean size of the ordered (crystalline) domains, which may be smaller or equal to the grain size; $\mathrm{K}$ is a dimensionless shape factor, which has a typical value of $0.89 ; \lambda$ is the $\mathrm{x}$-ray wavelength; and $\beta$ is the line broadening at half the maximum intensity after subtracting the instrumental line broadening in radians. This quantity is also sometimes denoted as $\Delta(2 \theta) ; \theta$ is the Bragg angle (Ref. 26).

\section{Mechanical Testing}

The tensile specimen was prepared from SRPE welded in the conditions of preheating and nonpreheating. The welded specimens were prepared as a rectangular strip with the dimensions of $25 \times 150 \times 10 \mathrm{~mm}$ (three samples were used per each condition), which was used to analyze the tensile strength of the weld (Ref. 20). The tensile strengths of the welded specimens were tested by UTM, and then the broken areas and types of fracture of the welded specimens were considered to determine the quality of the weld (Refs. 20, 27, 28).

For the stiffness test, the welded SRPE pipes were applied by a compression load at $5 \%$ deflection according to American Society for Testing Materials Standard F2435-15 (ASTM F2435-15) and Thai Industrial Standard 2764-2559 (TIS 2764-2559) for considering the strength of the welded SRPE (Refs. 8, 9). The pipe stiffness was calculated from the equation as follows: Stiffness $=\mathrm{F} /(\mathrm{L} \times \Delta \mathrm{Y})$, where $\mathrm{F}=$ compressive force $(\mathrm{N}), \mathrm{D}=$ length of specimen $(\mathrm{mm})$, and $\Delta \mathrm{Y}=$ changes in vertical deflection (mm) (Refs. 8, 9). Finally, the welded pipe was sealed at both ends and then filled with water into the lidded pipe for testing water leakage and hydrostatic pressure.

\section{Results and Discussion}

\section{Welding and Investigation}

From visual inspection, the welded pipes from the preheat and nonpreheat conditions exhibited good welds and displayed complete joint penetration without defects and discontinuities at the surface - Fig. 3 . The size of the width, convexity, and root of the weld were found to be approximately $32.0,5.0$, and $1.0 \mathrm{~mm}$, respectively. The average 
sizes of the welded pipes were measured and summarized in Table 1 and were in the range according to TIS 2764-2559 and AWS G1.10M:2001 (Refs. 9, 22).

From the radiographic tests (Fig. 4), the x-ray images of welded specimens from the preheat and nonpreheat conditions showed the three contrast zones, such as dark black, black, and bright black, which were assigned as the areas of HDPE, steel-reinforced HDPE, and weld, respectively. The $\mathrm{x}^{-}$ ray image of the preheated welded specimen (Fig. 4A) showed the complete weld without any defects observed along with the welded areas. For the x-ray image of specimens from the nonpreheat welding, it was found the HDPE and steel-reinforced HDPE zones had no defect and a smooth surface, but the welded area showed the discontinues that formed inside the welded material as shown in Fig. $4 \mathrm{~B}$. These volumetric indicators inside the nonpreheated weld were assigned as a void that came from impurities such as moisture, as well as volatile and processing additives (including the immediate shrinkage of the weld). This caused the high cooling rate in nonpreheat welding and generated the void in the material at a high temperature. From the RT result, it indicated the preheated condition could eliminate these impurities and also soften the material during the welding process, which solved the problems of any defects inside the weld.

Phase components of the welded SRPE at the welded area and HDPE base were characterized by $\mathrm{x}$-ray diffraction. The XRD patterns of the HDPE base and welds obtained from preheated and nonpreheated welding exhibited the diffraction peaks as shown in Fig. 5A-C, respectively.

The characteristic peaks of all specimens appeared at the $2 \theta$ of 21.4 and 23.7 deg corresponding to the diffraction planes of (110) and (200), respectively. These diffraction peaks agreed with the orthorhombic structure of HDPE as reported elsewhere (Refs. 23, 29). In addition, the XRD showed the broad peak at $2 \theta$ approximately 20 deg, which was typically assigned to the amorphous phase of HDPE. It confirmed that the structure of the HDPE base before and after welding consisted of the semicrystalline structure of both amorphous and crystalline phases. Moreover, it was found that the broad peak of the specimens after being welded was significantly changed into the more sharper shape, similar to the other crystalline peaks in the pattern. It indicated the hot extrusion welding changed the crystallinity and lamellar crystalline size of HDPE. Therefore, the amorphous characteristics and crystallinity of the welds, including the size of lamellar crystalline, were considered. The \% crystallinity and lamellar crystalline size of the welded SRPE and HDPE base were calculated and summarized in Table 2.

From the crystallinity calculation results, it was found that the HDPE at the base showed lower crystallinity
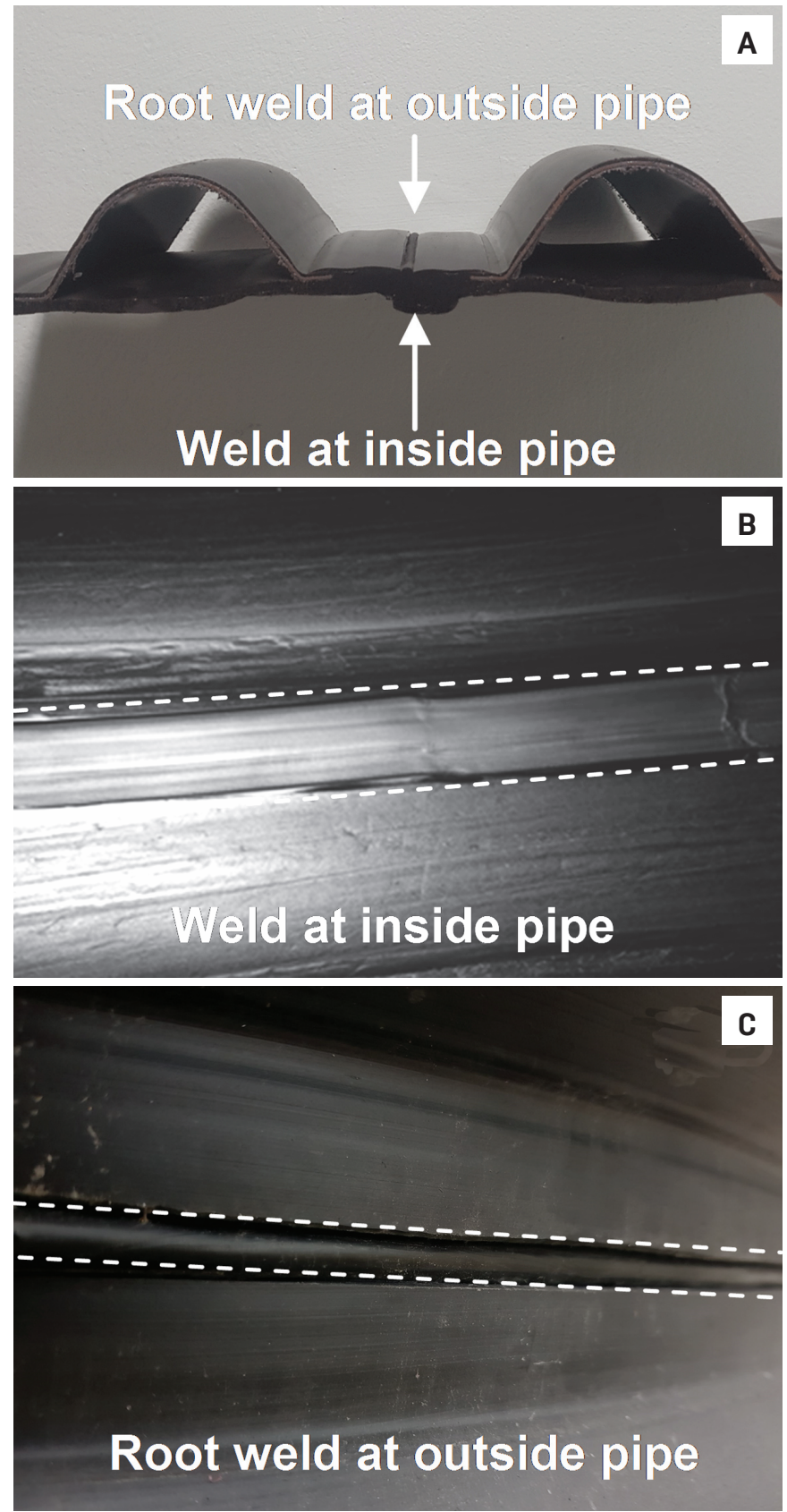

Fig. 3 - The generality of welded SRPE: A - Cross section; B - inside; $C$ - outside.

(64.65\%) than that of the preheated (65.80\%) and nonpreheated welds (70.15\%). By the Scherrer equation, the calculated size of lamellar at the plane of (111) of the HDPE base, for both preheated and nonpreheated welds, were found to

Table 1 - Visual Inspection of Welded SRPE Pipe

\begin{tabular}{|c|c|c|c|c|c|c|c|c|c|}
\hline \multirow[t]{3}{*}{ Welding Conditions } & \multirow{3}{*}{$\begin{array}{l}\text { Inside Diameter } \\
\text { (mm) }\end{array}$} & \multirow{3}{*}{$\begin{array}{l}\text { Outside Diameter } \\
\text { (mm) }\end{array}$} & \multirow{3}{*}{$\begin{array}{l}\text { Pitch Range } \\
\text { (mm) }\end{array}$} & \multirow{2}{*}{\multicolumn{2}{|c|}{$\begin{array}{l}\text { Wall Thickness } \\
(\mathrm{mm})\end{array}$}} & \multicolumn{3}{|c|}{ Weld Size $(\mathrm{mm})$} & \multirow{3}{*}{$\begin{array}{l}\text { Weld } \\
\text { Defect }\end{array}$} \\
\hline & & & & & & \multirow[t]{2}{*}{ Convex } & \multirow[t]{2}{*}{ Width } & \multirow[t]{2}{*}{ Root } & \\
\hline & & & & Internal & Total & & & & \\
\hline Preheat & 1201.0 & 1332.0 & 154.7 & 5.20 & 10.09 & 5.15 & 32.20 & 1.00 & No defect \\
\hline Nonpreheat & 1201.1 & 1332.2 & 154.7 & 5.25 & 10.10 & 5.05 & 32.50 & 0.95 & No defect \\
\hline
\end{tabular}




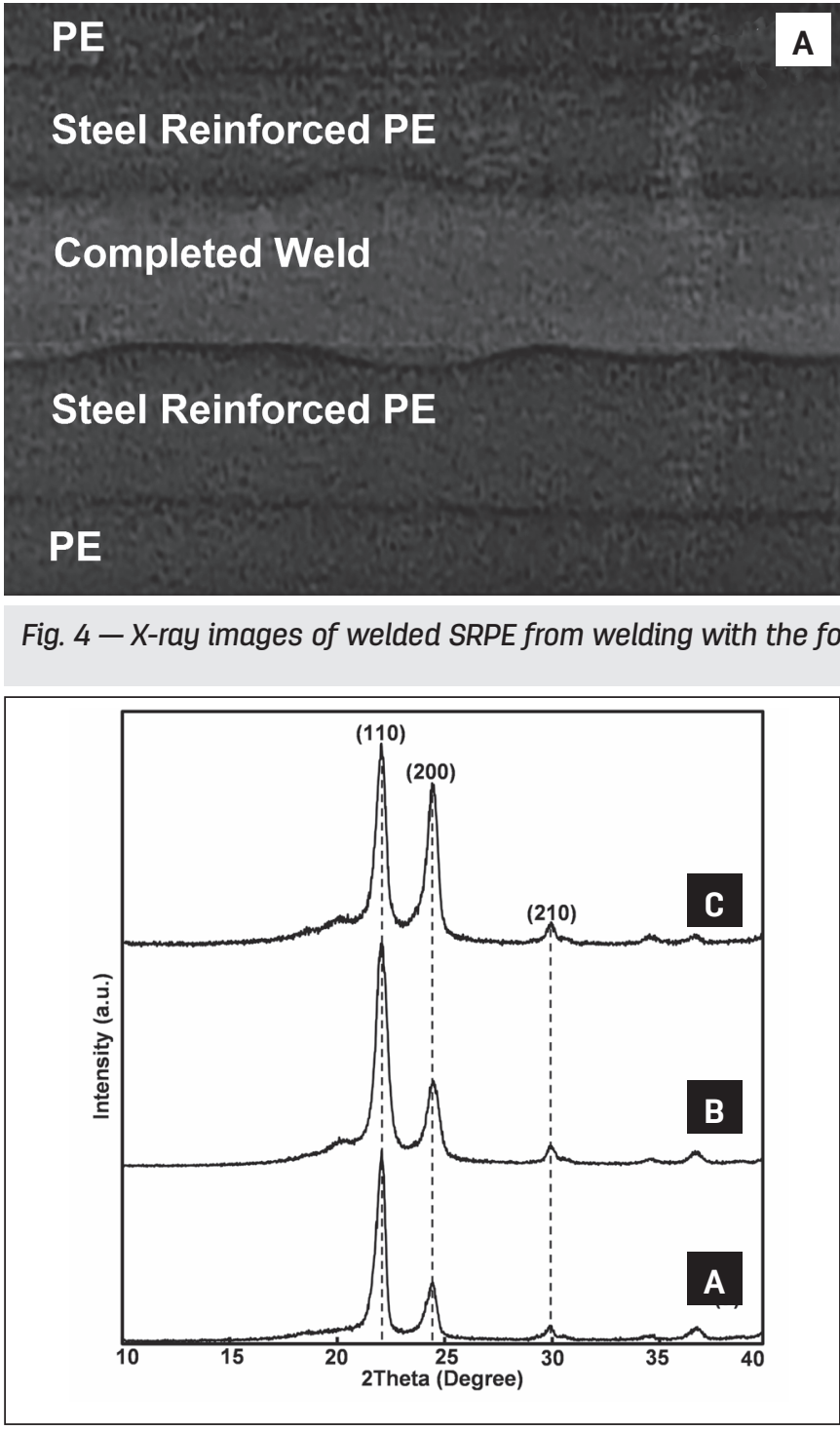

Fig. 5 - XRD patterns of welded SRPE: A - HDPE base; B preheated weld; $C$ - nonpreheated weld.

be 29.70, 28.72, and $24.30 \mathrm{~nm}$, respectively. At the plane of (200), the crystallite size of the HDPE base, preheated and nonpreheated welds, was found to be $28.76,27.45$, and $22.94 \mathrm{~nm}$, respectively. These results indicated the lamellar size of the weld was decreased after welding while the crystallinity was increased. The crystallinity and crystallite size of the nonpreheated weld was extremely changed from the

\section{Steel Reinforced PE}

Void formed

Steel Reinforced PE

PE

HDPE base, which might indicate the welding process without preheating condition could not control the crystallinity and crystallite size of materials. In the case of the preheated weld, it was found that the crystallinity and crystallite size were close to those of the HDPE base, which might demonstrate that the preheated welding could control the crystal structure by reducing heat loss and the cooling rate during welding.

\section{Mechanical Testing}

The tensile testing results of the welded specimens from preheating and nonpreheating were compared as shown in Fig. 6. The tensile strength (Fig. 6A) of the welded specimens from the preheated and nonpreheated conditions was found to be 46.04 and 31.01 MPa, respectively. The elongation at the break (Fig. 6B) of the welded specimens from welding with and without preheat was found to be 98.53 and $64.13 \%$, respectively.

In addition, the types of failures (ductile and brittle ruptures) in the welded specimens after testing were considered for the weld quality of the joint (Refs. 20, 27, 28). The results showed the welded specimens from the preheated condition had good joint quality because they showed ductile ruptures after breaking at the base position of the test specimens, outside the welding area - Fig. 7A. It indicated preheat welding could control weld quality, crystallinity, and crystallite size of the weld. For the welding without the preheat condition, it was found that the specimens exhibited brittle ruptures and were broken at the welding area, which indicated the joint in the

Table 2 - XRD Result of Welded Pipe

\begin{tabular}{lcccc} 
Specimens & $2 \theta(\mathrm{deg})$ & Plane & Lamellar Crystallite Size (nm) & $\%$ Crystallinity \\
\hline \multicolumn{1}{c}{ Base } & 21.4 & $(110)$ & 29.70 & $64.65 \%$ \\
& 23.7 & $(200)$ & 28.76 & 28.62 \\
Preheated Weld & 21.4 & $(110)$ & 27.45 & $65.80 \%$ \\
& 23.7 & $(200)$ & 24.30 & $70.15 \%$ \\
Nonpreheated Weld & 21.4 & $(110)$ & 22.94 & \\
& 23.7 & $(200)$ & & \\
\hline
\end{tabular}



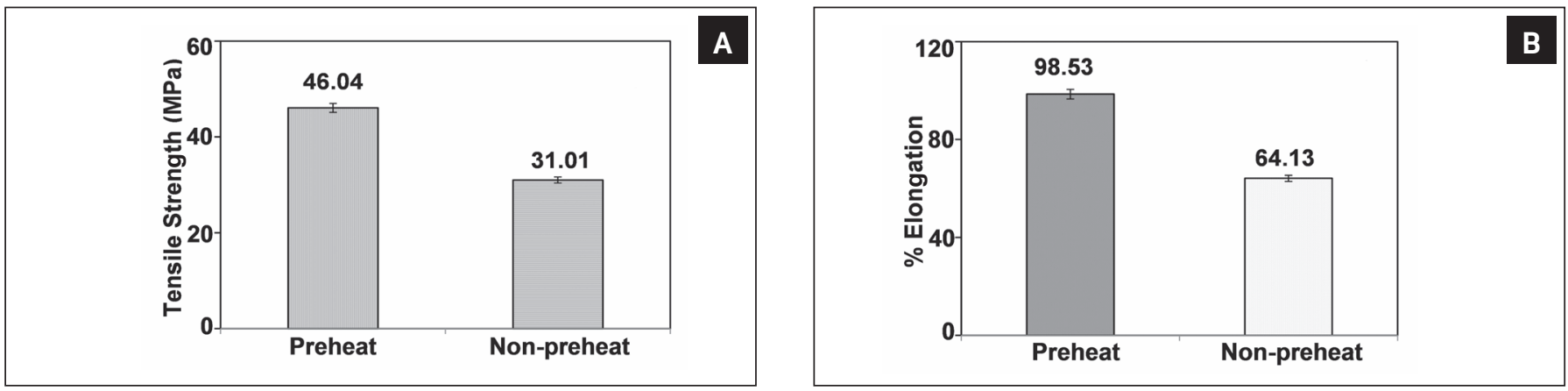

Fig. 6 - The tension testing results: $A$ - Tensile strength; B - elongation of specimens from welding conditions of preheat and nonpreheat.
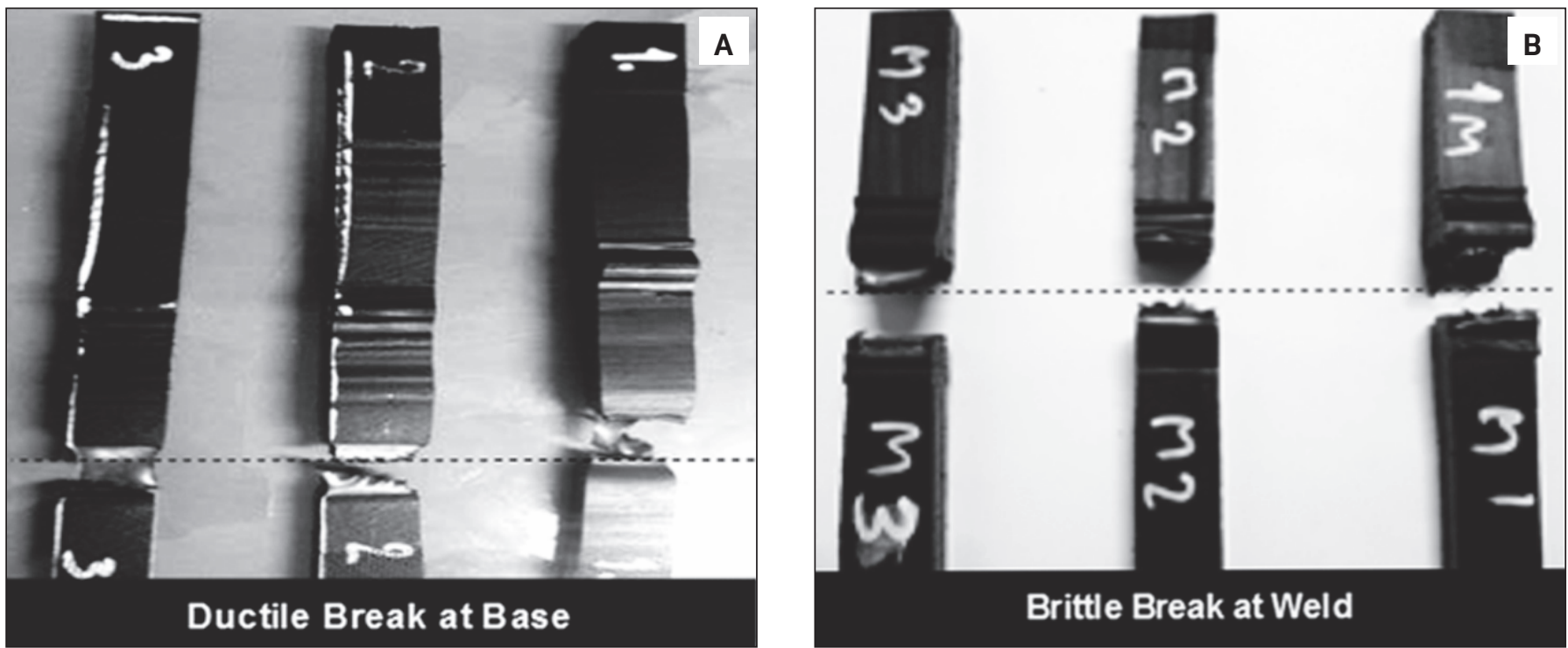

Fig. 7 - The welded specimens after tension test: A — Preheated specimens; B - nonpreheated specimens.

nonpreheated specimens had poor quality as shown in Fig. 7B. This was due to the void that formed inside the weld, which decreased the strength of the welded specimens. From the compressive test (Table 3), the pipe specimens from welding, with and without preheat conditions, revealed stiffness of 0.41 $\mathrm{MPa}$ at the stress of 5\% deflection according to ASTM F241215 and TIS 2764-2559 (Refs. 8, 9). Moreover, the test specimens were further tested at the high stress of $40 \%$ deflections, and it was found the welded specimens could stand without cracking at the weld and base areas. This could explain that the compressive force was dispersed by the strength of the reinforced steel; therefore, the weld and HDPE base received no damage.

For the water leak and hydrostatic pressure tests, the SRPE pipe welded at both cover lids was filled with water and kept for four weeks. The sealed tank showed no leakage at the weld and base material observed by water leakage testing. In addition, we found the welded SRPE pipe could endure hydrostatic pressure up to $0.18 \mathrm{MPa}$ without any water leakage - Fig. 8. After testing by using the pressure over $0.18 \mathrm{MPa}$, it was found the water was able to leak out from the internal pipe wall near the reinforced steel. From these results, it might be concluded the welded SRPE pipe could be used for water drainage, sewage, water supply industrials, and nonpressure applications.

\section{Conclusions}

Steel-reinforced polyethylene (SRPE) corrugated pipe was welded by extrusion welding in preheated and nonpreheated conditions. From visual and radiographic inspections, the welded SRPE from the preheated condition exhib-

Table 3 - Pipe Stiffness Testing Result

\begin{tabular}{|c|c|c|c|c|}
\hline Welding Conditions & Specimen Size $(\mathrm{mm})$ & Load at $5 \%$ & ID after Test & Pipe Stiffness at \\
\hline & Length & Deflection (N) & (mm) & 5\% Deflection (MPa) \\
\hline Preheat & 1201.0 & 15,000 & 1128.0 & 0.41 \\
\hline Nonpreheated & 500.3 & 14,996 & 1128.8 & 0.41 \\
\hline
\end{tabular}




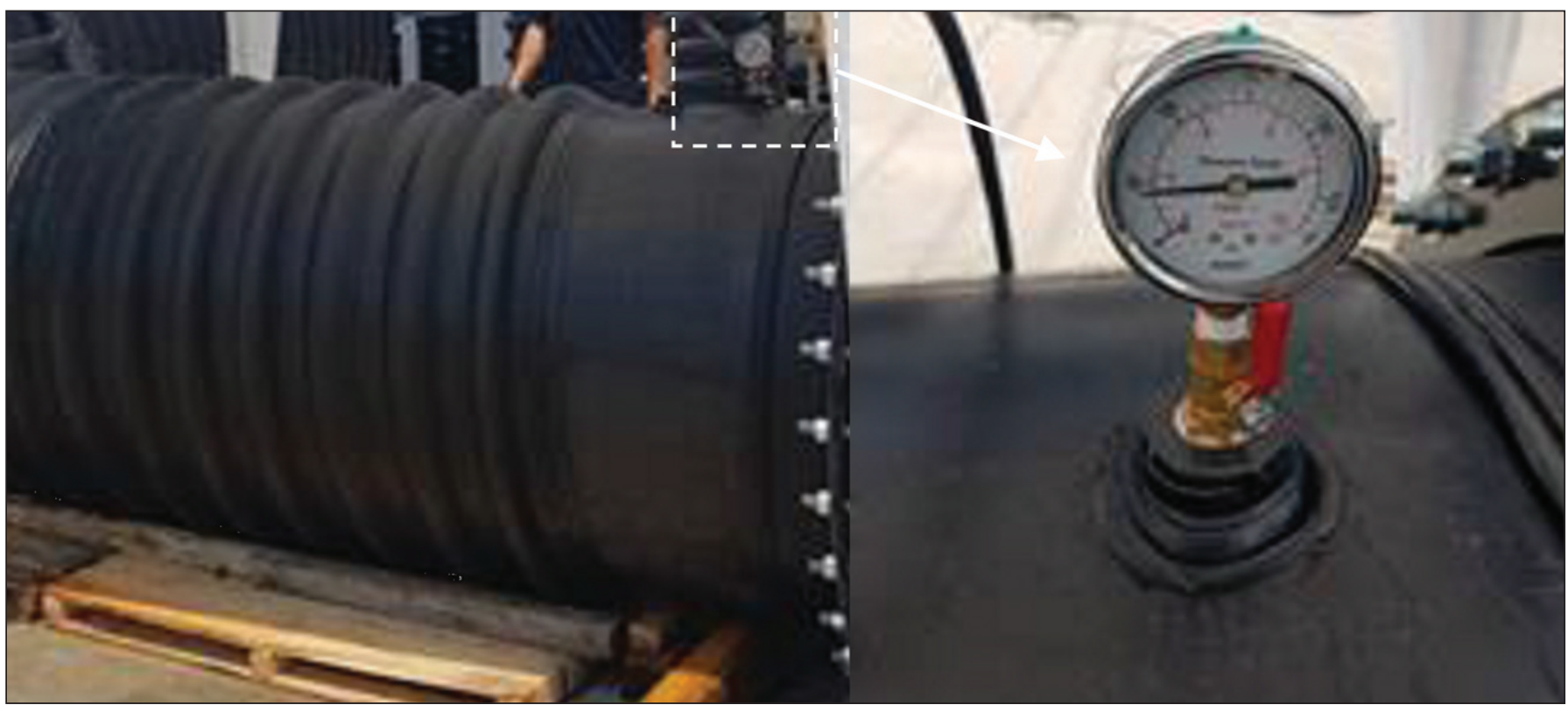

Fig. 8 - Hydrostatic pressure test.

ited a complete-joint-penetration weld without defects while that of the nonpreheated weld had a void formed inside. By $\mathrm{x}$-ray diffraction (XRD) characterizations, the welds from preheated and nonpreheated conditions exhibited diffraction patterns that agreed with the orthorhombic structure. The crystallinity and crystallite size of the preheated weld was similar to unwelded high-density polyethylene (HDPE) while the nonpreheated weld was extremely changed. From the tensile results, the preheated weld specimens showed ductile ruptures at the HDPE base. In the case of the nonpreheated weld, the specimens showed brittle ruptures at the welding area because the void formed inside the weld. For compressive testing, superior results were presented due to the steel reinforcement. The preheated specimens could also endure the stress of $40 \%$ compression without cracking at the base and welding areas. Moreover, no leakage at the weld and the base was observed after water leakage and hydrostatic pressure tests under a pressure of $0.18 \mathrm{MPa}$. From the overall results, it was clearly concluded that preheated welding was able to control the weld quality, crystallinity, crystallite size, and mechanical properties of the welded SRPE.

\section{Acknowledgments}

The authors would like to thank Mr. Siwawut Sornnil and SR.PE GROUP Co. Ltd. for the supporting materials and instruments.

\section{References}

1. Schaaf, F. J. 2008. Development of Code Case N-755: Use of Polyethylene (PE) Plastic Pipe for Section III, Division 1, Construction and Section XI Repair/Replacement Activities, $16^{\text {th }}$ International Conference on Nuclear Engineering, ICONE16-48495, pp. 963-969. DOI: 10.1115/ICONE16-48495
2. Walsh, T. 2016. The Plastic Piping Industry in North America, Applied Plastics Engineering Handbook: Processing, Materials, and Applications: $2^{\text {nd }}$ Ed., pp. 697-716. DOI: 10.1016/B978-0-323-390408.00033-X

3. Terzi, N. U., Yılmazturk, F., Yıldırım S., and Kılıç, H. 2012. Experimental investigations of backfill conditions on the performance of high-density polyethelene pipes. Experimental Techniques 36(2): 40-49. DOI: 10.1111/j.1747-1567.2010.00691.x

4. Yu, K., Morozov, E. V., Ashraf, M. A., and Shankar, K. 2017. A review of the design and analysis of reinforced thermoplastic pipes for offshore applications. Journal of Reinforced Plastics and Composites 36(20): 1514-1530. DOI: 10.1177/0731684417713666

5. Lee, B. Y., Kim, Y. K., Hwnag, W. G., Kim, J. S., and Lee, S. Y. 2012. Improvement of butt-welding characteristics of double wall polyethylene pipes. Metals and Materials International 18(5): 851-856. DOI: 10.1007/s12540-012-5016-5

6. Zheng, H. W., Xiang, S. H., and Chang, L. 2013. Study on production technique of the metal reinforced polyethylene spiral corrugated pipe. Advanced Materials Research 634-638: 2040-2043. DOI: 10.4028/www.scientific.net/AMR.634-638.2040

7. Khatri, D. K., Han, J., Parsons, R. L., Young, B., Brennan J. J., and Corey, R. 2013. Laboratory evaluation of deformations of steel-reinforced high-density polyethylene pipes under static loads. Journal of Materials in Civil Engineering 25(12): 1964-1969. DOI: 10.1061/(ASCE)MT.1943-5533.0000779

8. ASTM F2435-15, Standard Specification for Steel Reinforced Polyethylene (PE) Corrugated Pipe. 2015. West Conshohocken, Pa.: ASTM International. DOI: 10.1520/F2435-15

9. TIS 2764-2559, Standard Specification for Steel Reinforced Polyethylene Corrugated Pipe. 2016. Bangkok, Thailand: Thai Industrial Standards Institute.

10. Hongtao, H., and Hickey, T. 2017. Steel Reinforced Polyethylene Corrugated Pipe Applications \& Inspection Standards. Sichuan Goldstone Orient New Material Equipment Co. Ltd., pp. 1-17, pdf.directindustry.com/pdf/sichuan-goldstone-orient-new-materialequipment-co-ltd/steel-reinforced-polyethylene-corrugated-pipe-applications-inspection-standards/123361-721834.html, accessed 29 May, 2019.

11. Sun, Y., Jia, Y. F., Haroon, M., Lai, H., Jiang, W., and Tu, S. T. 2019. Welding residual stress in HDPE pipes: Measurement and numerical simulation. Journal of Pressure Vessel Technology 141(4): 
041404-1-041404-9. DOI: 10.1115/1.4043463

12. Niou, S., Chaoui, K., Azzouz, S., Hamlaoui, N., and Alimi, L. 2018. A method for mechanical property assessment across butt fusion welded polyethylene pipes. International Journal of Advanced Manufacturing Technology 97: 543-561. DOI: 10.1007/s00170-0181908-y

13. Rojek, M., Stabik, J., and Muzia, G. 2010. Thermography in plastics welding processes assessment. Journal of Achievements in Materials and Manufacturing Engineering 41: 40-47.

14. Balkan, O., Demirer, H., and Yildirim, H. 2008. Morphological and mechanical properties of hot gas welded PE, PP and PVC sheets. Journal of Achievements in Materials and Manufacturing Engineering 31(1): 60-70.

15. Grewell, D. A., Benatar, A., and Park, J. B. 2013. Plastics and Composites Welding Handbook. Hanser Publications, Ohio.

16. O'Brien, A. 2015. Welding Handbook, $9^{\text {th }}$ ed., Vol. 5, Plastics. Miami, Fla.: American Welding Society. pp. 517-566.

17. Haque, M. S., Kumar, M., and Khan, A. 2015. Hot gas welding of plastic: Fundamentals \& importance. Invertis Journal of Science and Technology 8(4): 1-4.

18. Rotheiser, J. 2009. Hot Gas Welding, Joining of Plastics, $3^{\text {rd }}$ ed. Carl Hanser Verlag, Munich, Germany. pp. 321-334. DOI: 10.3139/9783446445956

19. Troughton, M. J. 2008. Handbook of Plastics Joining: A Practical Guide, $2^{\text {nd }}$ ed., Extrusion Welding. William Andrew Inc., N.Y., pp. 73-79.

20. Chaichawalit, A., Tippayasam, C., Yingsamphancharoen, T., Sornnil, S., and Kaewvilai, A. 2018. A semi-automatic welding machine based on hot air extrusion with preheating function for joining of steel reinforced PE corrugated pipe. The $1^{\text {st }} M R S$-Thailand 2017 Int. Conf. Proc., pp. 114-119.

21. Chaichawalit, A., Kaewvilai, A., Yingsamphancharoen, T., and Tippayasam, C. 2018. Semi-Automatic Welding Machine based on Hot Air Extrusion for Plastic Pipe, TH-Petty Patent, No. 1803002088.

22. AWS G1.10M: 2001, Guide for the Evaluation of Hot Gas, Hot Gas Extrusion, and Heated Tool Butt Thermoplastic Welds. 2001. Miami, Fla.: American Welding Society.
23. Pelto, J., Verho, T., Ronkainen, H., Kaunisto, K., Metsäjoki, J., Seitsonen, J., and Karttunen, M. 2019. Matrix morphology and the particle dispersion in HDPE nanocomposites with enhanced wear resistance. Polymer Testing 77: 105897. DOI: 10.1016/j. polymertesting.2019.105897

24. Shirkavand, M. J., Azizi, H., Ghasemi, I., and Karabi, M. 2018. Effect of molecular structure parameters on crystallinity and environmental stress cracking resistance of high-density polyethylene/TiO $\mathrm{Tin}_{2}$ nanocomposites. Advances in Polymer Technology 37(3): 21719. DOI: $10.1002 / a d v .21719$

25. Dai, H., and Peng, J. 2017. The effects of welded joint characteristics on its properties in HDPE thermal fusion welding. Modern Physics Letters B 31(15): 1750185. DOI: 10.1142/ S0217984917501858

26. Srisuwan, N., Kumsri, N., Yingsamphanchareon T., and Kaewvilai, A. 2019. Hardfacing welded ASTM A572-based, high strength, low-alloy steel: Welding, characterization, and surface properties related to the wear resistance. Metals 9: 224. DOI: 10.3390/met9020244

27. ASTM F2634-15, Standard Test Method for Testing of Polyeth ylene (PE) Butt Fusion Joint Using Tensile-Impact Method. 2015. West Conshohocken, Pa.: ASTM International. DOI: 10.1520/F2634-15

28. BS EN 1555-1: 2010, Plastic Piping Systems for the Supply of Gaseous Fuels Polyethylene. 2010. London, UK: British Standards Institute.

29. Sami, A., David, E., and Fréchette, M. 2010. Procedure for evaluating the crystallinity from x-ray diffraction scans of high and low density polyethylene/ $\mathrm{SiO}_{2}$ composites. Annual Report - Conference on Electrical Insulation and Dielectric Phenomena: 5724069. DOI: 10.1109/CEIDP.2010.5724069

CHAYANEE TIPPAYASAM and ATTAPHON KAEWVILAI (attaphon. k@cit.kmutnb.ac.th) are with the Department of Welding Engineering Technology, College of Industrial Technology, King Mongkut's University of Technology North Bangkok, Bangkok, Thailand.

\section{Authors: Submit Research Papers Online}

Peer review of research papers is now managed through an online system using Editorial Manager software. Papers can be submitted into the system directly from the Welding Journal page on the AWS website (aws.org) by clicking on "submit papers." You can also access the new site directly at editorialmanager.com/wj/. Follow the instructions to register or log in. This online system streamlines the review process, and makes it easier to submit papers and track their progress. By publishing in the Welding Journal, more than 70,000 members will receive the results of your research.

Additionally, your full paper is posted on the American Welding Society website for FREE access around the globe. There are no page charges, and articles are published in full color. By far, the most people, at the least cost, will recognize your research when you publish in the world-respected Welding Journal. 